\title{
A New Approach of Image Processing Teaching by Gagne Learning Conditional Theory
}

\author{
Liang-Yuan Hsiung, Mei-Ting Lin, and Mu-Hui Lai
}

\begin{abstract}
In Taiwan, Adobe Photoshop has been regarded by many departments of Information \& Communication and Design as a core course as well as a set of professional techniques. However, throughout the learning process, most teachers have viewed Adobe Photoshop merely as application software. The shortage of effective instructional events in a classroom often prevents students from acquiring the accurate and effective techniques. As a result of low intention, students have played off spending more than regular time on image processing in an ineffective learning routine.

This study aimed to effectively improve students' competence of image processing through an eight-week course that features a series of professional instructional events. Students were divided into two groups to work on the same set of aerial images. The first 15 students in the control group were left on their own device to process those images. The other 15 students in the experiment group were following instructions designed according to a model consisting of nine steps of instructional events based on the Condition of Learning theory by Robert. M. Gagné. The experiment group students were instructed to go through those steps repeatedly for practice, with respective outcome at each step recorded for comparison with the control group.

The results indicated that, compared to those students working on their own, students in the experiment group were better motivated and their works were of higher quality, which indicated that their attitude toward learning and cognitive capability had improved through instructions designed based on cognitive theory and a model of instructional events.
\end{abstract}

Index Terms-Instructional events, Attitude, Cognitive capability.

\section{FORWARD}

Adobe Photoshop functions virtually as a magician for images. It provides unlimited changes in exercise of colors and knows no limit in exercise. In the hands-on practice, nevertheless, we have noticed quite a few students would make use of the Fixed Parameters provided by the Adobe Photoshop. Very often they would like to use the Batch file

Manuscript Received March 14, 2011

Liang-Yuan Hsiung, assistant professor, is with the Department of Information \& Communications, Kun Shan University , Tainan, Taiwan R.O.C. (Phone:886-6-205-1230; Cell:0935-925-456; fax: 886-2-28362239; e-mail:apexat@gmail.com)

Mei-Ting Lin, a lecture, is also with the Department of Information \& Communications, Kun Shan University, Tainan, Taiwan R.O.C. (e-mail: gua_gua@mail2000.com.tw).

Mu-Hui Lai, director (Dr.) of computer center, is with the Department of Electrical Engineering, Nei-Hu Vocational High School, Taipei, Taiwan, R.O.C.(e-mail:Imh0104kimo@yahoo.com.tw;1mh0104@mail.nihs.tp.edu.tw to do Retouch and take other unsound steps and functions in the operations. As a result, they tend to unnecessarily waste a great amount of time. Moreover, with the incorrect direction in the production, a great majority of students could never possibly live up to their Technical Expectations. In turn, they would inevitably run into frustration.

An instructor would, therefore, fail to live up to students' expectation at all if he/she fails to guide students through the sound and correct methodology and concepts but, instead, teach students to purely operate the Adobe Photoshop Function keys alone to have the students to work with Adobe Photoshop through "tries and errors" alone. That would be a significant flaw in the teaching process and would underline the instructor's inadequacy in preparation of teaching and professional know-how. How to make best possible use of the teaching method to enhance students' competence and to boost students' psychological soundness and interests in the learning? The answer to this question represents the very motivation behind the present study.

\section{RESEARCH PURPOSE}

Adobe's founders Chuck Geschke and John Warnock Adobe Systems Incorporated in 1982 for the purposes of presenting the computerized words and images through printing faithfully and precisely. In 1983, they successfully launched the know-how of Adobe PostScript, offering a completely new device for words and images, dubbed as the revolution of desktop print. To date, over $90 \%$ of professional creators throughout the world have equipped Adobe Photoshop into their desktops. A great majority of those professional hands, nevertheless, simply could not demonstrate the Adobe Photoshop in full. Many users have just reached to the effect in the use of the tools, regrettable enough.

What facing students in an image processing course are not confined to the learning of the tool itself alone. The outcomes of the image processing are equally or even more important. It is not the case that each and every image file is optimal enough in solution, brightness, color and hue.

This is especially true when it comes to the point that many image files come from different sources and would be in vastly differing conditions of production. In the case of aero photos, satellite photos and such image files of high degree difficulty, for instance, we must take into account such intricate factors of topography, weather, brightness and angle of flight which tend to frustrate professionals' competence in production and processing. Using aero analysis and concept of teaching students would, therefore, help enhance students 
in effect of their learning and professional performance and, in turn, boost their confidence.

In the early 1980 s, some British scholars already started up analysis of professional competence and, in turn, set up indices of professional competence [1]. Through such efforts, they intended to foster four interrelated components in job competence. Through such efforts, students could learn the accurate retouching skills to accomplish the expectation of learning in the technical education within a very short period of time.

In turn, students would take an added interest in learning. That was known as the most prompt and effective means of Adobe Photoshop teaching.

\section{RESEARCH LITERATURES}

Merrill held [2]: "A teaching method which is duly adjusted in line with the contents of learning should be the optimal and most effective one." Before teaching process, therefore, it is necessary to analyze the contents to be learnt before the instructor adjusts the methods and strategies of teaching to best orient them to the learners.

The contents to be learnt can be duly classified along with the different cognition or methods of expression. The contents after being duly classified may well foster the demands anticipated from students based on the characteristics to accomplish the maximum possible effect of learning through adjustment of the teaching strategies and methods[3] [4] [5] [6] [7].

Taking a lesson is quite an intricate process itself. Whenever one can accumulate the hands-on experiences by a scientific means through cognition of the learning process, it is termed a sound principle of learning. The principles of learning so accumulated will constitute collectively into a specified mold, known as the learning oriented theory [5].

Gagné held that a teaching process is composed of a series of facts in external factors provided to the learners. In the perspective of psychology, such "Learning Events" should be the very prerequisites to obtain the results of learning.

The author, therefore, noticed that while teaching students to learn image processing, the instructor should try to have students understand the orientation and the goals of processing, to what extent the students should learn. To put it in more understandable terms, it is necessary to have the interrelationship of the four key prerequisites represented through the "The Job Competence Model" [1]:

1) Technical Expectations

2) Managing Contingencies

3) Managing Different Work Activities

4) Managing with Coordination of The Interface with The Work Environment

\section{RESEARCH METHODOLOGY}

The present study is for the purposes of enabling students to upgrade their competence in image processing and to accomplish the effect anticipated in the professional skills within a very short period of time. In the methodology, the students were categorized into two panels to experience the training programs of one course, using the same aerial images file (Figure 1). In the aerial image, the students of the counterpart panel were given image processing assignment and records. After that, in Phase II, they utilized the nine teaching steps and the molds of design operation of Robert. M. Gagné Condition of Learning to teach five students in the second panel to repeat the learning process and record the steps and results for an inter-comparison. Based on the cognition theory and teaching application molds, the instructor would notice that it would arouse students' interests to easily accomplish the effect of teaching, produce quality images to enhance students' attitude and competence in cognition.

\section{RESEARCH LIMITATIONS}

The learning stratum might be conducive in the curricular design. In the actual practice, there would inevitably be some restrictions (Soulsby, 1975 ; Wang Hsiu-ling, 1988). A range of instructional models including those that are indirect (i.e., student-centered and constructivist), direct (i.e., teacher directed), and cooperative in nature.

In the range of applicability, for instance, it would be more applicable to students who learn experiences and concepts of such software. In turn, it would be more applicable to the professional technique oriented education, individualized education or collective education of the same attributes instead of teaching in huge classes of different attributes. To the learning stratum itself, the logic subsequence analyzed through the teaching materials (Figure 1) would not necessarily comply with the substantial teaching subsequence or the learning subsequence of each and every student.

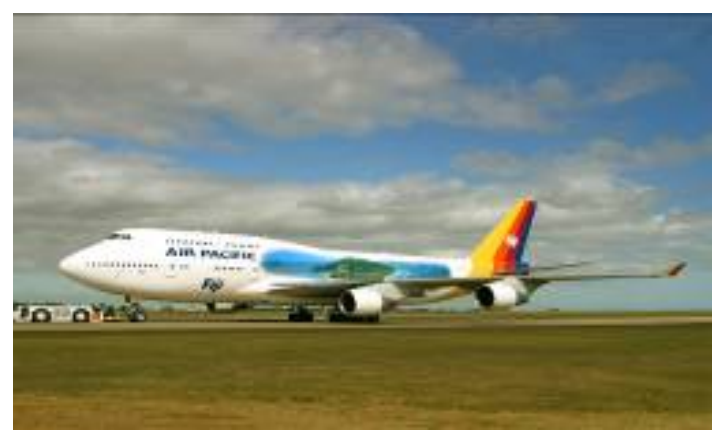

Figure1. The aerial image as teaching material

\section{STEPS AND PROCESSES}

To solve the inadequacy in the Adobe Photoshop functional design and to enable students to accomplish the effective work roles, the instructor could utilize the -photographic skills to produce the information based on the differences and similarities in the image and process instead of experiences or observation alone which could only obtain piecemeal information. The process and steps of the present study (Figure. 2): 


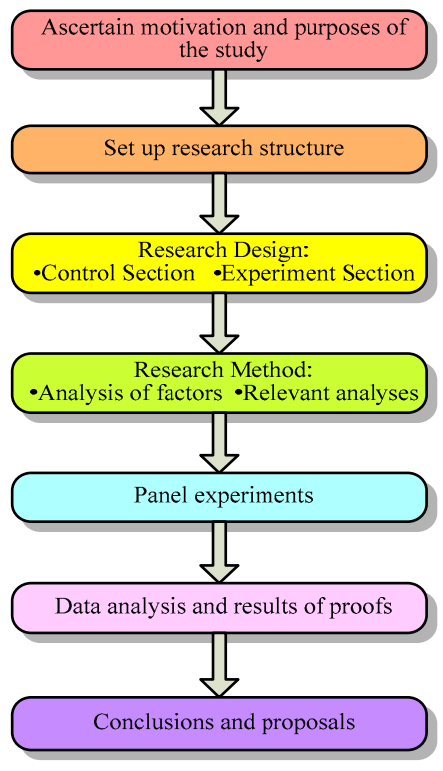

Figure 2 The Flowchart of Research Structure on Image Processing.

\section{CONTROL SECTION AND EXPERIMENT SeCtion}

There are a lot of Adobe Photoshop teaching books showed only the functions in them, however, many related studies, especially those in the resource-based field, witness that superior performance is always derived from the possession of unique and difficult-to imitate skills, knowledge, resources, assets or competencies[12]. Under this situation, conscious and informed strategies become intentional efforts to include information beyond what is required for mastery of academic or vocational content.

The research is urgently needed to achieve an in-depth understanding of how and why core competencies contribute to firm performance in contingent contexts; even more in order to adapt quickly and effectively to the increasingly changing nature of both internal and external business environments.

During the processing, the researchers observed several strategies for delivering academic and vocational content so that all these two groups become a platform for instruction in the other. In order to approve this experimental research, instructors use samples from vocational coursework to teach academic concepts (Gagne theory), so that students may see methods and applications coming from the vocational context in which the information and theories were originally presented. At the same time, instructors also use teaching samples from academic coursework, so that students can tell same images from teachers' works applications coming from the academic-theoretical context in which they were originally presented. Under the team's original definition, curriculum integration could entail the incorporation of academic material beyond what would be required for vocational mastery, or the presence of vocational material and references beyond what might normally be expected in academic instruction. Under the new definition, both of these scenarios occur simultaneously.

In order to solve the insufficient designed in both functions and teaching skills, the researchers may utilize the work roles to attain the effective learning for students. The steps are as below (see Figure 3):
1) Describe the outcomes and products in activity not describe a job routine.

2) Utilize the literature and the image process skills to proceed the experimental research, not through experience and observation.

3) Use the functional map to achieve the result of competence analysis. Managing Different Work Activities

4) If a step is incomplete in teaching routine, the teacher should return and finish it to do a strict comparison or analysis again so that it can arouse the students' interest.

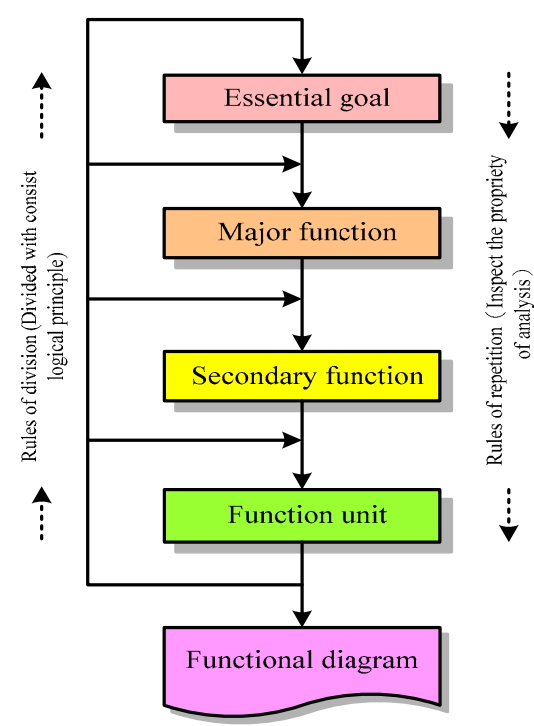

Figure 3 Work competence derived from two rules of functional diagram

The teaching model offered by Gagne is, most of all, characterized by being capable of taking care of both the students' learning process and the instructors' teaching process [8]. Gagne stressed that in the class teaching, the instructors should appropriately design a series of teaching activities in line with internal messages of the students to help students operate effectively within the process [9]. Besides, in a variety of design for teaching activities in his teaching model, Gagne kept an eye on the theories of information processing and took a comprehensive consideration of the empirical results of the effective teaching design [10]. That means he virtually looked after both sides which are quite worthwhile to teaching of students. Would the entire teaching mold live up to the anticipated goals? This calls for further empirical study.

The production steps of the experiment panel (Figure 5) and the counterpart one were duly recorded and the image processing effect was duly analyzed with reference to the comparative color figures to locate the optimal portfolio, taking the experience value to judge the level of the entire image files which were taken as the referential grounds in the image processing.

Adobe Photoshop image processing proceeds in manners which allow students to "Learn by Doing"; acquiring proficiency in very short time. The pressure is on for this academic/industrial reciprocal cooperative module, especially meeting customer's demands and beating deadlines. To achieve maximal efficiency, one could employ the Gagne theoretic and steps as a model and listed the nine steps as below (Figure.4) [11]: 


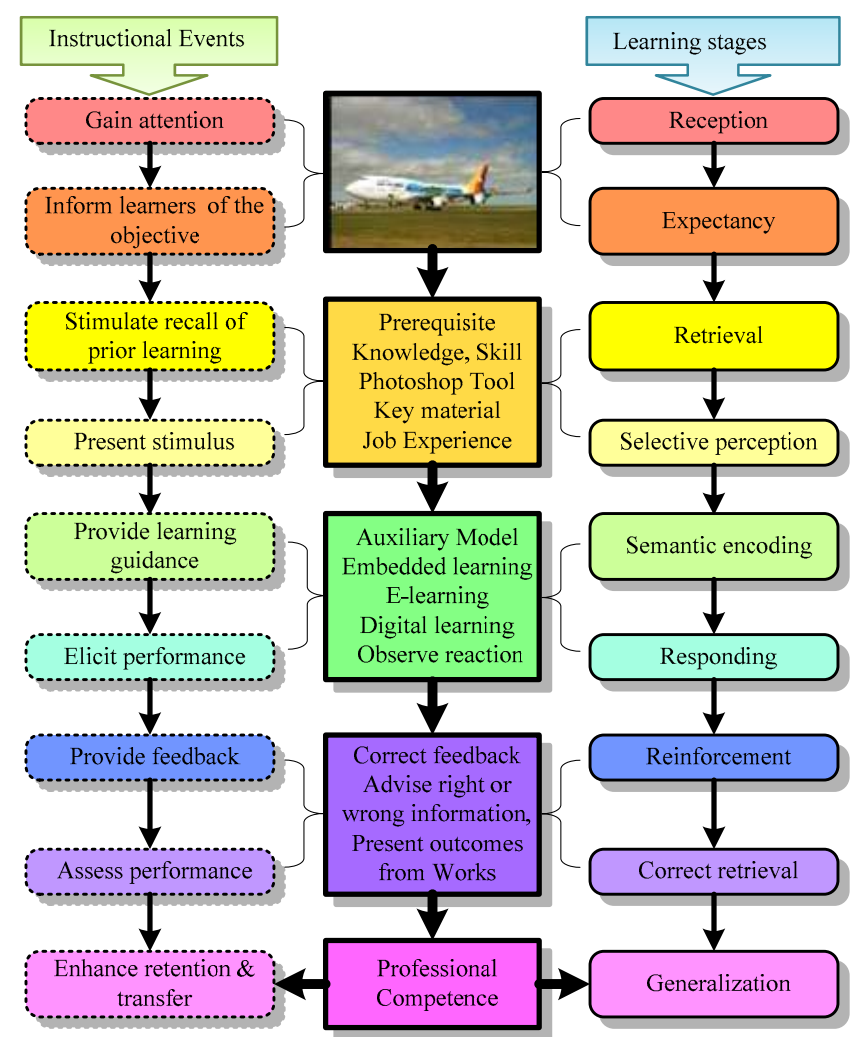

Figure 4 The application of nine instructional events of Gagne Learning conditional theory of Aerial Image Model

All these teaching processes in the above model are abided by the nine events of Gagne's learning theory and are included in the learning stages,

1) Attention

2) Expectancy

3) Retrieval to Working Memory

4) Selective Perception

5) Semantic Encoding

6) Retrieval and Responding

7) Reinforcement

8) Retrieval Clues

9) Generalize

"Conditions of Learning Theory" by Gagne is beneficial to practical archives application. How to entice and intrigue the students to grasp better understanding of the equipment and relevant functions, through proper teaching and effective accomplishment of realistic projects is of primal importance.

The researcher stresses on applying "Conditions of Learning Theory" by Gagne, to create interaction with students. Such practice not only permits the students to fully realize industrial competitiveness, but also reduces waste/abuse of available resources in hi-tech learning.

The key factors from retouching image are cognitive color,

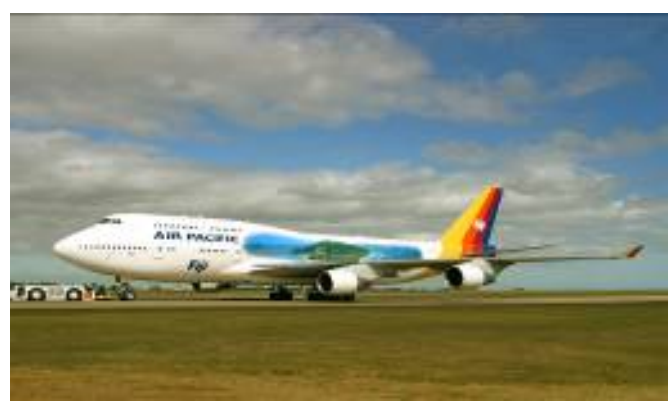

Figure 5 The Original Image Ready for Students Technical Training. cognitive image, attitude, intellectual skills, enlightenment of arts. All these factors are needed by teaching courses expectation as a questionnaire in most vocational education and technical school in Taiwan.

The researcher takes the original photo (Figure.5) and final approval (Figure.6) which are offered by business shop to present in teaching course for students.

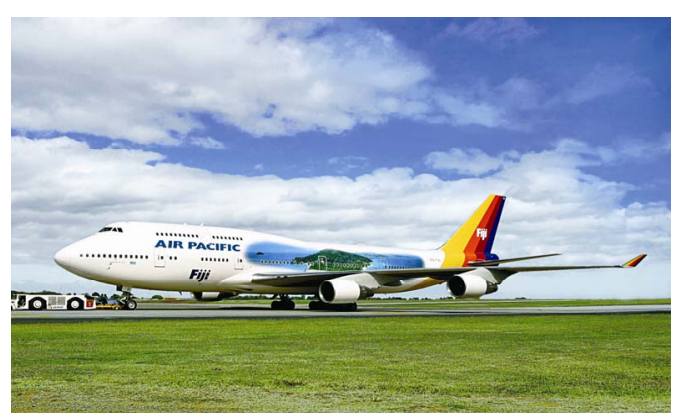

Figure 6 The Expected Outcomes for Students.

The questionnaire had good reliability and validity: the overall reliability of the questionnaire was good, with a Cronbach's Alpha coefficient of .874; the validity was acceptable and the test results from experts and enterprises are listed as below (Table 1).

TABLE 1 THE EFFECTIVE DIFFERENTIATE BETWEEN CONTROL GROUP AND EXPERIMENTAL GROUP

\begin{tabular}{lll}
\hline Instruments 15 Students each & $\begin{array}{l}\text { Control } \\
\text { group }\end{array}$ & $\begin{array}{l}\text { Experimental } \\
\text { group }\end{array}$ \\
\hline Cognitive color & $8 \%$ & $17 \%$ \\
Cognitive image & $21 \%$ & $48 \%$ \\
Attitude & $31 \%$ & $61 \%$ \\
Intellectual skills & $31 \%$ & $44 \%$ \\
Enlightenment of arts & $11 \%$ & $16 \%$ \\
\hline
\end{tabular}




\section{STEPS AND PROCESSES}

As science $\&$ technology are advancing in each and every passing day, more and more curricula are computerized. Computerized teaching oriented software and curricula will become increasingly improved. It is necessary to take into detailed account the control design of the curricular design. Otherwise the attractive pictures alone would even puzzle the learning process and foil the results of learning in the computerized teaching if not matched with sound presentation and connection in the connotation of the curricula.

1) Color separation skills and experience still remain very important factor for retouching images.

2) More helpful and easier to the students' cognition by analyzing aerial image.

3) Students in the experiment group were better motivated and their works were of higher quality, which indicated that their attitude toward learning and cognitive capability

The present study is conducive to the successful location of a more optimal model in image processing through curricular production in the model of teaching for image processing. In turn, it enables instructors to help students learn the correct law in the color modification within only a short period of time to arouse added interests of students. Subsequently, students in the professional technology education would gain better benefits in the learning process. The findings and results yielded in the study could benefit Adobe Photoshop regarding how to further better the skills in image processing.

\section{ACKNOWLEDGMENT}

Liang Yuan Hsiung, Mei-Ting Lin and Mu-Hui Lai would thank the support of Chief of the Information \& Communication Department, Dr. S. H. Chang and the students in Kun Shan University, Taiwan, which have joined and assisted the research in year of 2010 and would take the results to apply the NSC project to proceed further more researches. All the research routines acquired any helps are also acknowledged.

\section{REFERENCES}

[1] Mansfield, B. \& Mitchell, L. (1996). Towards a Competent Workforce. Gower Publishing, Aldershot, November 1996.

[2] Merril, M. D. (1994). Instructional design theory. In C. M. Cliffs, NJ: Educational Technology Publications.

[3] Clark, R.C. \& Mayer, R.E. (2003). E-learning and the science of instruction. Pfeiffer.

[4] Smith, P. L., \& Ragan, T. J. (1999). Instructional Design, 2nd ed. New York: John Wiley \& Sons.

[5] Gagne, R. \& Driscoll, M. (1988). Essentials of Learning for Instruction (2nd Ed.). Englewood Cliffs, NJ: Prentice-Hall.

[6] Merrill, M.D. (1983). Component Display Theory. In C.M Reigluth (Ed.) Instructional design theories and model: An overview of their current status. Hillsdale NJ: Lawrence Erlbaum Associates, Publishers.

[7] Gagné R. M. (1965). The Conditions of Learning. New York: Holt, Rinehart and Winston.

[8] Gagné, R. M. (1974a). Expectations for school learning. Bloomington, IN: Phi Delta Kappa.

[9] Gagné R. M. (1989). Studies of learning: Fifty years of research. Tallahassee, FL: Learning Systems Institute.
[10] Gagné R. M. (1986). Instructional Technology: The research field Journal of Instructional Development, 8(3), 7-14.

[11] Killpatrick, L. (2001). Gagne's Nine Events of Instruction. In B. Hoffman (Ed.), Encyclopedia of Educational Technology. HTML retrievedOctober3,20.

[12] Wang, Y., Lo, H. P., \& Yang, Y. H. (2004). The constituents of core competencies and firm performance: evidence from high-technology firms in china. Journal of ENGINEERING AND TECHNOLOGY MANAGEMENT. 21. 249-280

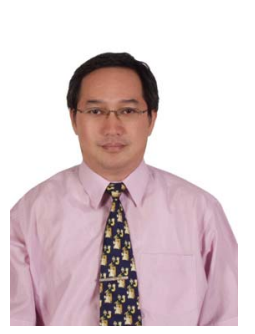

Liang Yuan Hsiung, born in Taichung Taiwan, majored in Printing Industry at Chinese Culture University in 1996. He won the Master Science Degree in Pittsburg State University, USA in 1991 and also achieved $\mathrm{Ph} \mathrm{D}$. at National Taiwan Normal University in 2010. His backgrounds are focused on Printing and Multi-media. Now he serves as an assistant professor in Kun Shan University of Science \& Technology, Taiwan. His main fields include printing technology application on high-tech, image process (Photoshop), interactive multi-media, color management, enterprise studies, entrepreneurship, estimating, satellite \& aerial image process etc.

He served in Navy and studied two years program of German in National Defense Ministry in 1982-1983 and then passed the qualified examination at German language center. He also worked at Shanghai Printing Company Taipei and at China Color Printing Company for printing foreign trade division for over 15 years and also worked as factory manager almost 10 years in Hwa Kang Printing Works in Taipei. His publication titled "The digital printing estimating" published in Taipei, Taiwan in 2003. Now he has many projects for NSC, MOE and MOEA and published papers in many International Conferences and EI journals.

Dr. Hsiung works as an assistant professor in Kun Shan University and lectures as an expert in government unit and joins Carl Duisberg Association as a secretary general and member of a council in Taiwan, R.O.C.

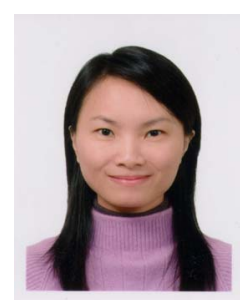

Mei Ting Lin was born in Taipei Taiwan and majored in Design, Color Scheme and Image process including Photoshop, Flash and Illustrator etc. In 2004 she won the Design Master in Kun Shan University, Taiwan. Her backgrounds includes light construction, digital image processing, plane design and arrangement design. Now she serves as a Lecturer at Information \& Communications in Kun Shan University of Science \& Technology, Taiwan.

She worked in some business shops and companies before teaching in Kun Shan University. Her experience makes her become the welcomed teacher in school. She also joined and presented her papers at many Conferences in China mainland, Korea, Japan and USA. She won the first prize in designing LED works in 2009 and during that time she led students attend many competitions and earned many awards.

Lecture Lin works as a lecture in Kun Shan University for years. She edited and published an expertise book titled "Form Principles" in Taipei 2008. She is also in charge of the member reviewer for Adobe Certiport Taiwan.

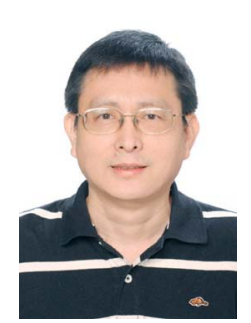

Mu-Hui Lai, born in Chang-hua County, Taiwan, R.O.C., won the Ph D. at National Taiwan Normal University in 2009. His backgrounds are focused on majored in Information Technology Education and Electric \& Electronic Education. He served as a director in computer center, Nei-Hu Vocational High School, Taipei, Taiwan. His main fields include information technology education, data mining, electronic design automation, and creativity education etc.

$\mathrm{He}$ has been worked in Chinese Productivity Center (Ministry of Economic Affairs) as a lecture and serviced in SMEs for five years as a consultant. He currently is a teacher in Nei-Hu Vocational High School and composes student teams to participate many competitions in Taipei and national domestic areas obtaining excellent award.

In 2009 and 2010 Dr. Lai instructed students and won twice the International School CyberFair PLATINUM AWARD which is verified by Kim's Record. He published for over 20 expertise books including operating system, data mining, electronic design automation, creativity education, computer auxiliary design and computer education. 